ISBN 978-93-84468-94-1

International Conference on Education, Business and Management (ICEBM-2017)

Bali (Indonesia) Jan. 8-9, 2017

\title{
Factors of opening Chinese Language Tutorial School in Bangkok
}

\author{
Dr. Tosaaporn Mahamud, Mr Chao Yi \\ Post graduate school of business admiration Kasembundit University, Bangkok
}

\begin{abstract}
The purpose of the study is to determine factors and behavior of consumer in selecting Chinese language tutorial school in Bangkok. The samples were selected from 218 set of check list and rating scale questionnaires as a tool. Statistical application used for data analysis was percentage, mean, standard deviation, t-test, Chi Square, One-way Anova, and regression analysis. Researcher suggested as follows: 1 . The institute should open on Sunday with courses work for one year and tuition fee cost not more than 12,000 baht per year. 2. The institute should recruit Chinese language teachers who have unconventional teaching techniques make it easy to learn, teaching evaluation should be done regularly, managing institute with the system, well trained service personnel to accommodate students and their parents. 3. Tutorial school should set comparable tuition fee and special activity fee appropriately, school supplies, payments with credit cards, and discount when come with the group. 4. Institute should locate in easy access location, convenient transportation with adequate parking spaces, and suitable class room environment.
\end{abstract}

Keyword: Factors, behavior

\section{Introduction}

Chinese language as a foreign language that gained popularity greatly because nowadays Chinese plays a very important role in the economic and trade area, also has invested in various businesses between Thailand and China. In present day, Chinese teaching caused widespread expansion, not only in large school or higher education level but in all levels of education of all sizes. However, the opening of Chinese school with the problem when the demand increase rapidly. From the reported of the Office of the Private Education Commission revealed that there are 1,983 tutorial schools in Thailand, located in Bangkok 487 tutorial schools, located in provinces 1,496 tutorial school, in the total of 74 provinces mostly school located near provinces with large population.

The statistics of the Ministry of Education in the year 2553 stated that there are 859,085 students in Bangkok, divided into kindergarten 121,965 students, elementary and high school 364,588 and 372,532 students. Special lessons are in the form of a tutorial of Thai Children whose age start at 3 years old, the adult will take additional English courses for everyday use and work. English tutorial school are growing in Thailand, there are over 20 institutes in Bangkok, such as A.U.A., Wall Streets, I genius, and language teaching school E.F. etc. which are located in shopping mall, such as Siam Square, Sri Lom, and Asoke shopping centers, etc. There are non-English school as well, such as Korea, K-top, K-edupak and Japanese school, such as School of language and cultures, waseda jap for example.

From the introduction above, researcher was interested in studying factors and behavior of consumer in selecting Chinese language tutorial school in Bangkok and use the results from the study to prepare a guideline for service development of Chinese language tutorial school in order to meet consumer requirement. 


\section{Purpose of the Study}

The purpose of the study is to determine factors and behavior of consumer in selecting Chinese language tutorial school in Bangkok.

\section{Results of the Study}

The results of factors and behavior of consumer in selecting Chinese language tutorial school in Bangkok as follows:

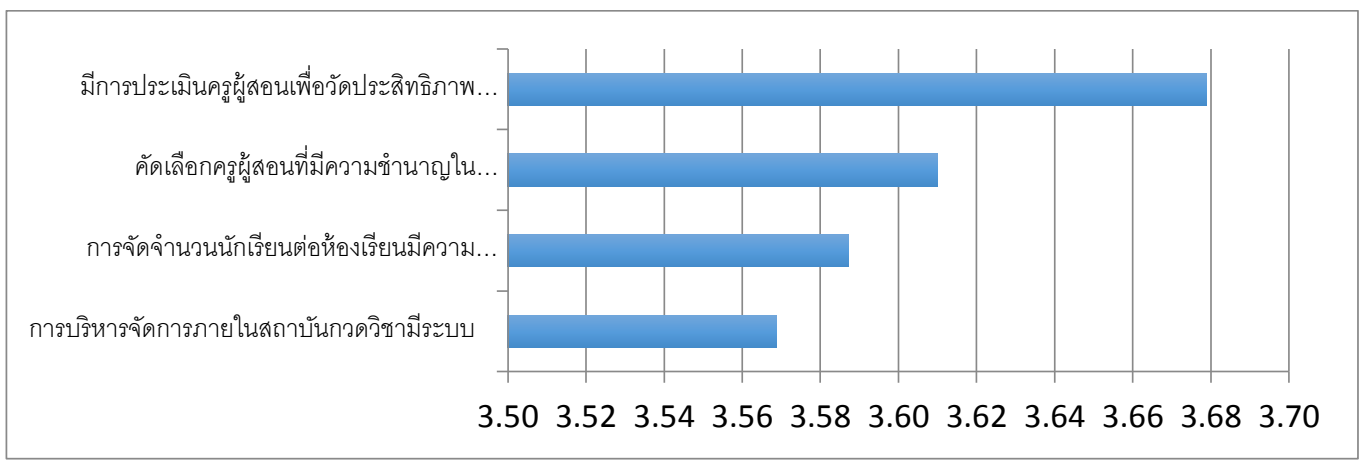

Fig. 1: Process aspect

From figure 1: the average picture of the opinion of factors and behavior of consumer in selecting Chinese language tutorial school in Bangkok regarding process aspect was at high level $(\bar{x}=3.61)$

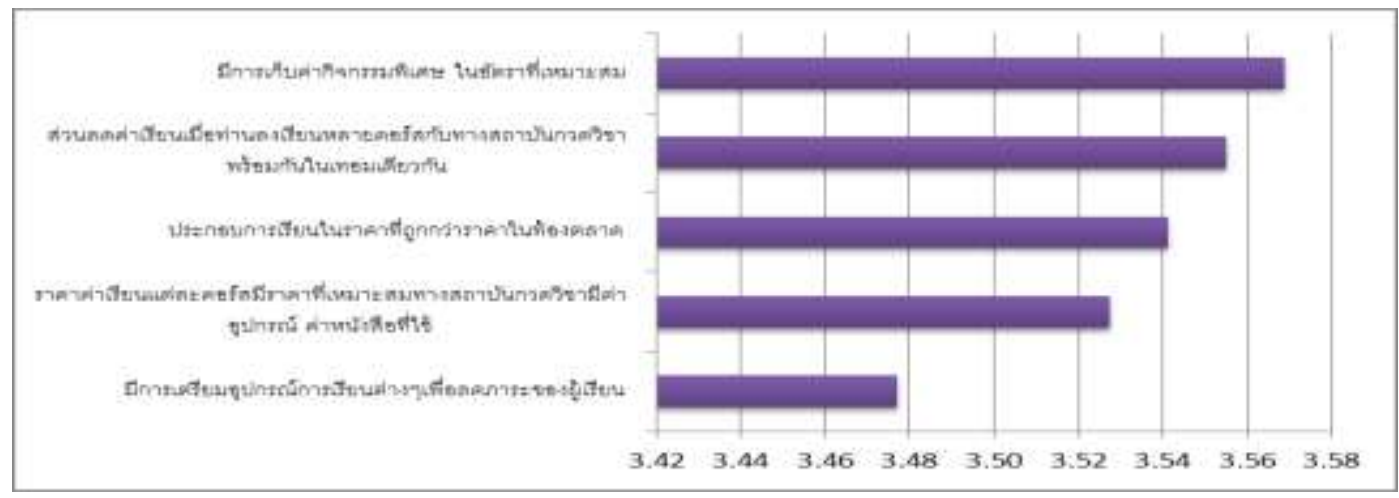

Fig. 2: prices aspect

From figure 2: the average picture of the opinion of factors and behavior of consumer in selecting Chinese language tutorial school in Bangkok regarding prices aspect was at high level $(\bar{x}=3.54)$.

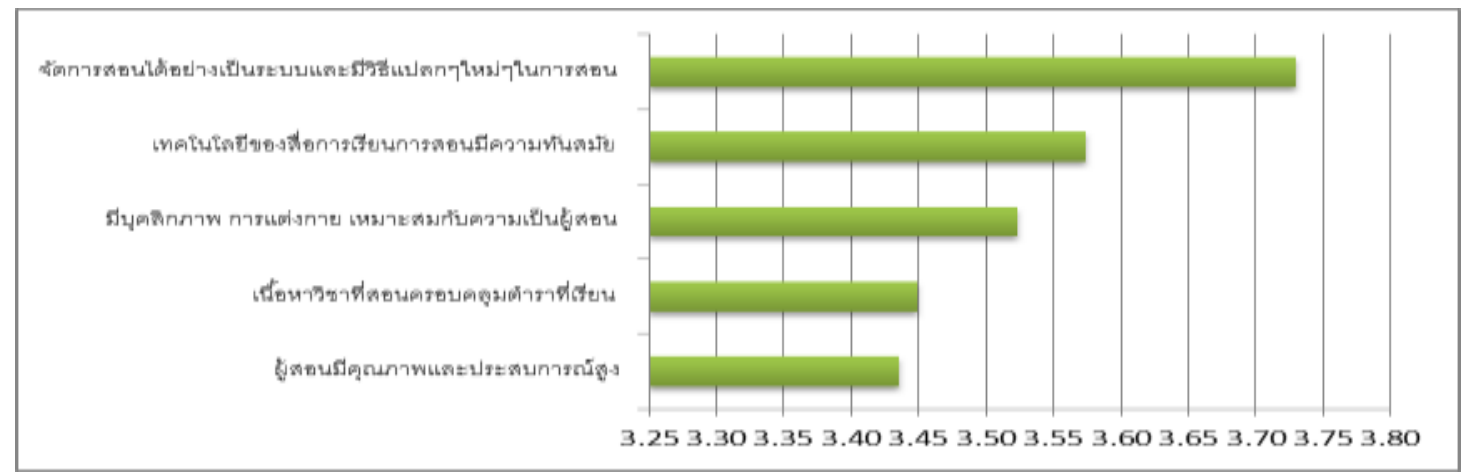

Fig. 3: Physical evidence and presentation aspect. 
From figure 3: the average picture of the opinion of factors and behavior of consumer in selecting Chinese language tutorial school in Bangkok regarding physical evidence and presentation aspect was at high level $(\bar{x}=3.54)$.

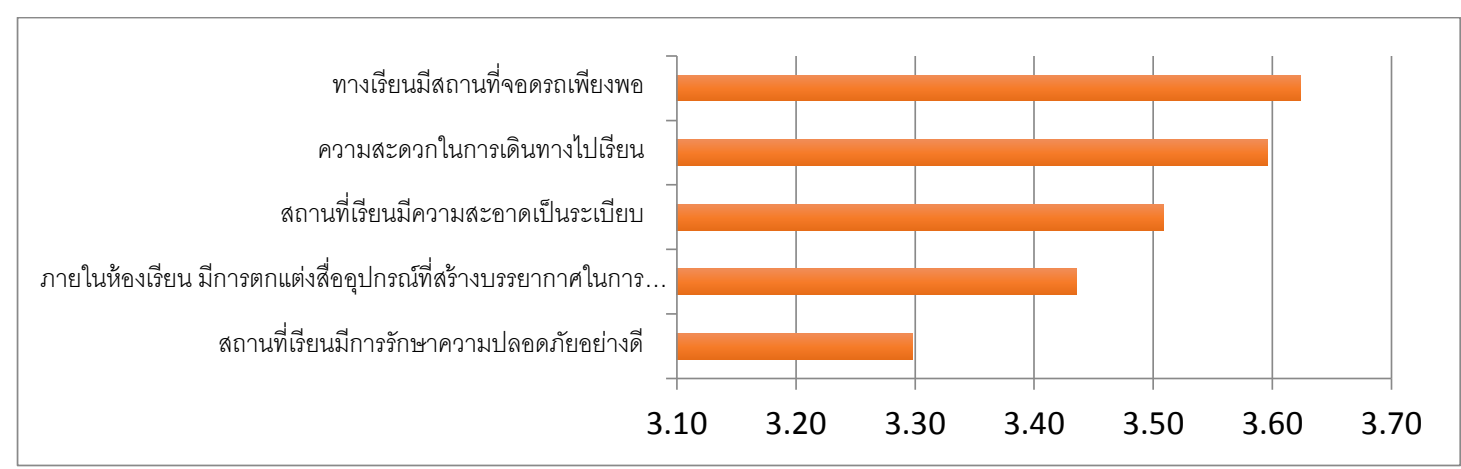

Fig. 4: Place of Chinese language institute aspect

From figure 4: the average picture of the opinion of factors and behavior of consumer in selecting Chinese language tutorial school in Bangkok regarding Place of Chinese language institute aspect was at high level $(\bar{x}=3.49)$.

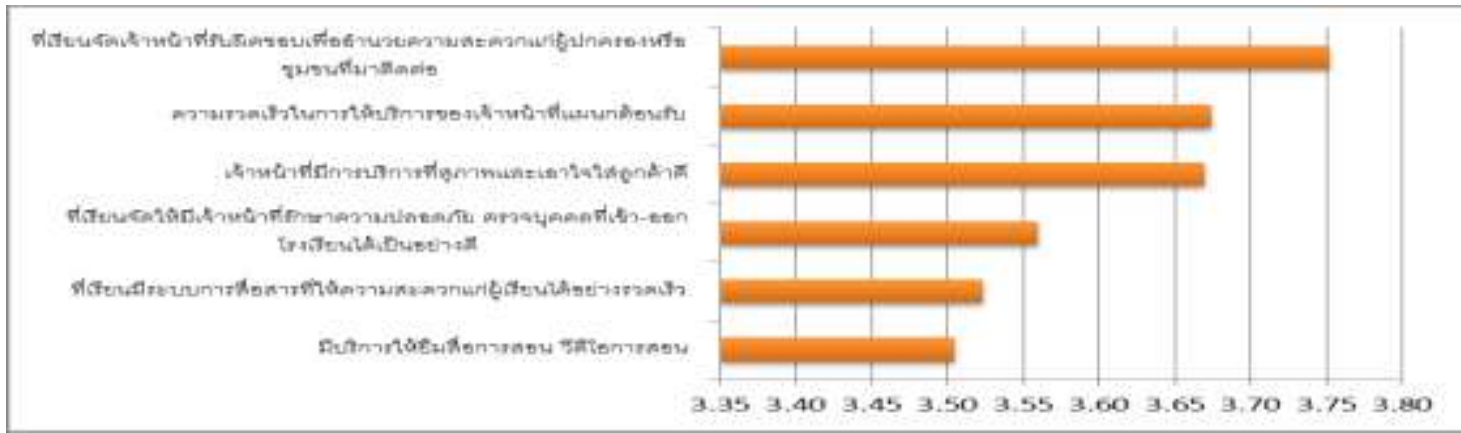

Fig. 5: Chinese language Institute personnel aspect

From figure 5: the average picture of the opinion of factors and behavior of consumer in selecting Chinese language tutorial school in Bangkok regarding Chinese language institute personnel aspect was at high level $(\bar{x}=3.61)$.

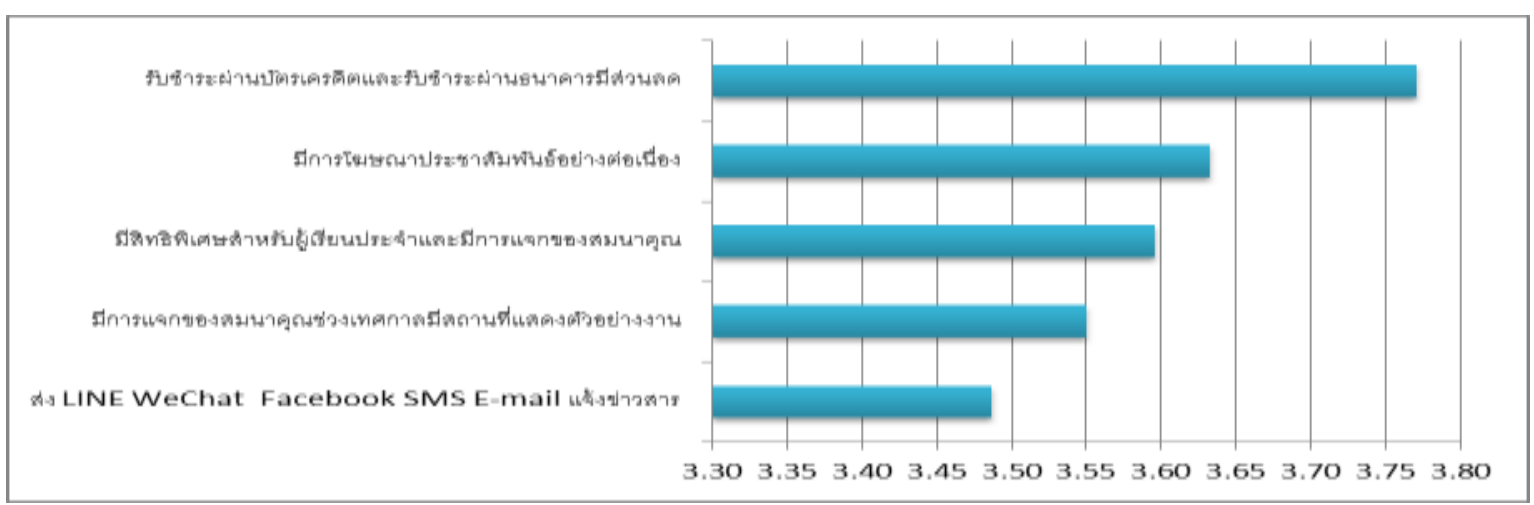

Fig. 6: Marketing promotion aspect.

From figure 6: the average picture of the opinion of factors and behavior of consumer in selecting Chinese language tutorial school in Bangkok regarding Marketing promotion aspect was at high level $(\bar{x}=3.60)$. 


\section{Suggestions from the Study}

Learning and teaching Chinese language is not only benefiting but gaining more friends, keep them happy with learning, and this is the most important feature of teaching Chinese language.

\section{The method of teaching:}

Regular Courses: create role play in the certain situation, such as playing games this is fun for the students who can participate that allow them in speaking, reading, and writing.

Advance courses: Advanced courses will teach reading, writing which adding more depth in this course. The learner will learn about the culture of doing business in long term, the business expansion with different business industries and this 3 principles:

1.Ability to understand the business linguistic, self-expression, and be able to communicate undoubtedly, including comprehend grammars and sentences as well.

2. The development of Chinese language teachers of training courses.

3. Prepare coursed syllabus for foreign students, adding an adjective and synonymous words. Expand sentences, messages, and grammars that become useful and ability to understand clearly.

With the scenario is designed to provide students with vocabulary, context, to engage in a conversation in real life situation, multicultural background that reflects the current globalization.

Curriculum and planning design, to be certain that the teachers are up to date in the understanding of new methods and creative thinking in the teaching of Mandarin through understanding by their design.

Online learning: Students, parents, and teachers can choose better online account to use for Chinese language learning outside classroom. Students have opportunity to review what they have learnt and enjoy more on animation, and sound recording.

\section{References}

[1] Thongchai Santivong. (2549). Consumer behavior of marketing. (11st edition), Prachum chang Publisher, Bangkok.

[2] Siriwan Saerirat, Parinrak Sitanont, Suppakorn Saerirat, and Ongard Patavanich. (2546). New Era of Marketing Management, Thammasarn publisher, Bangkok.

[3] Siriwan Saerirat \& Associate. (2543). Marketing principles. Theerafilm and Chitex Co., Ltd., Publisher, Bangkok.

[4] Siriwan Saerirat, Parinrak Sitanont, Suppakorn Saerirat, and Ongard Patavanich.(2541). Marketing Strategy and marketing management, Theerafilm and Chitex Co., Ltd., Publisher, Bangkok.

[5] Saeri Vongmonta. (2542). Analyze consumer behavior, Theerafilm and Chitex Co., Ltd., Publisher, Bangkok.

[6] Surasith Intae. (2551). Study relationship between marketing communication and traveling Behavior of Umphor Mae Sarieng, Mae Hong Sorn Province, Thesis, Master of Business Administration, Burapha University publisher.

[7] Prathana Suanboon. (2553). Factors affecting consumer behavior on purchasing furniture in Ratchaburi Province, Thesis, Master of Business Administration, Ratchaphat Moo ban Jormbung, publisher.

[8] Chinchai Kajonnatikul. (2553). Factors affecting consumer behavior on purchasing home Decoration furniture in Suphanburi Province, Thesis, Master of Business Administration, Kasetsart University pulisher.

[9] Arunwan Chombut. (2555). Factors affecting consumer behavior on purchasing sofa furniture In Pranakorn Sri Ayuthaya Province, Thesis, Master of Business Administration, Ratchaphat Valailongkorn University, publisher. 